\title{
Condom Use, Alcohol, and Reliability of Survey Data
}

\author{
Sergei V. Jargin ${ }^{1,}$ \\ ${ }^{1}$ Department of Public Health, Peoples' Friendship University of Russia, Moscow, Russia \\ "Corresponding author: Sergei V. Jargin, Department of Public Health, Peoples' Friendship University of Russia, Moscow, Russia. Tel/Fax: +7-4959516788, E-mail: sjargin@mail.ru
}

Received 2015 July 16; Revised 2016 January 04; Accepted 2016 January 19.

\begin{abstract}
Context: Many studies on alcohol misuse and related topics such as the use of condoms are based on surveys. However, some surveys are not free from biases. There are international differences in the attitudes of people to surveys, which should be taken into account reviewing the literature.

Evidence Acquisition: The search of the international literature was performed predominantly using PubMed. Russian-language professional publications were searched in the internet and the electronic library of eLIBRARY.ru. The literature was reviewed and summarized on the basis of the author's observations since 1970.

Results: The use of condoms in relation with alcohol drinking is largely dependent on personal characteristics; but, taken on overage, heavy binge drinking and alcohol consumption in sexual relations are risk factors for the nonuse of condoms. Besides, slowly progressing personality changes after a prolonged alcohol abuse and heavy binge drinking interfere with the risk perception and may contribute to the nonuse of condoms.

Conclusions: Surveys and opinion polls are valuable research tools and feedback mechanisms for administrative decisions; they should not be discredited by obtrusive questioning or asking for private information, with commercial or other purposes.
\end{abstract}

Keywords: Alcohol Abuse, Condoms, Sexually Transmitted Infections

\section{Context}

Many studies on alcohol misuse have been based on surveys (1-4). However, there are interregional differences. Evaluating results of surveys and opinion polls, it should be taken into account that these research tools have been largely discredited in Russia since the 1990s by a previous inadequate use: widespread obtrusive solicitations to partake in different surveys, often asking for private information (in the streets, per telephone, and also by agents coming to private homes). Accordingly, many people in Russia are "sick and tired" of questionnaires and tend to conceal their true opinions (5). This equally pertains to opinion polls and scientific surveys. Moreover, research itself is partly discredited in the public's eyes, as it is known about scientific misconduct and biases caused by conflicts of interests $(6,7)$. Many people generally mistrust authorities because of corruption, participation of civil servants in illegal affairs, disrespect for some laws and regulations, etc. The tendency to discredit surveys and opinion polls can be seen as a continuation of the Soviet-time attitude, when the "frame of mind of the working population" was monitored, but the data were kept secret or published in a biased form in accordance with the official ideology (5). Statements like "earlier research has suggested that, at least for drinking behavior, reports (by adolescents) can be regarded as being generally valid" (1) are in fact not supported by the references to studies from West Europe
(4), where the attitude to surveys is probably more responsible. However, biases in surveys can occur in any country. Misreporting about illicit drug use, abortions, seizures, and unsafe sexual behaviors has not been unusual $(8,9)$. Owing to the "Social Desirability" (SD) effect, respondents may deny or deflate their responses about undesirable behaviors and exaggerate desirable ones. Origins of this distortion range from denial through self-deception to deliberate self-impression management (10). The SD effect has been observed also in conditions of anonymity (8). As for the public opinion polls, they can misrepresent the attitudes of the population; in particular, the polls on health care should be treated with caution because of the frequent non-response (or "do not know") answers (11). Furthermore, in the author's opinion, a region-specific cause of untruthful answering can be lack of trust within the society (between the authorities and different social groups).

BagaBar functioning as a night club in Moscow is a source of noise all night through; windows of the neighboring apartment houses are vibrating from loud music. Complaints to the authorities do not help; kickbacks are probably paid.

\section{Evidence Acquisition}

Search of the international literature was performed predominantly using PubMed. Russian-language profes- 
sional publications were searched for in the internet and the electronic library of eLIBRARY.ru. The data from the literature was reviewed and summarized on the basis of the author's observations since 1970.

\section{Results}

The study (1) was based on a survey carried out in Arkhangelsk among adolescents 13 - 17 years old. In terms of sexual behavior, there was no difference in the odds ratios between binge drinking and non-binge drinking girls and boys for nonuse of condom during last sex (1). In other words, the adolescent binge drinking was reported to be not associated with nonuse of condom during last sex. It can be reasonably assumed that the study subjects answered the question "The last time you had sex did you or your partner use a condom?" (1). With "yes", without pondering that it is a research having potential significance for the public health. Respondents might be unwilling to admit to disapprove practices such as nonuse of condoms. Besides, according to our observations, there is mistrust towards official organizations and a concern that the information may leak through and become known to other people (12). However, responsibility about condom use has obviously increased contributing to the steady decline in the abortion rate in Russia for approximately the last 20 years (13).

The abortion rate in the former Soviet Union has been the highest in the world $(13,14)$, which was caused not only by insufficient availability of modern contraception, poor quality of condoms, etc., but also by irresponsibility of some males (15). The widespread alcohol misuse (16) was generally perceived as a contributing factor. The association between alcohol consumption and high-risk sexual behaviors is explainable within the scope of the alcohol myopia theory $(17,18)$. According to this theory, alcohol reduces cognitive capacity and causes people to focus on cues that are the most salient in the environment. Less salient cues require additional cognitive resources to process and are therefore less likely to be acted upon by an intoxicated individual (18). Furthermore, the effect of alcohol on cognition is supposed to be linear: the more intoxicated a person is the more pronounced the "myopia" becomes (19). In sexual encounters, the most salient cues are usually those that involve immediate sexual engagement. More distant cues, such as suspicion that the partner could be infected by a sexually transmitted infection (STI), are less salient. Therefore, when intoxicated by alcohol, the ability to consider less salient cues decreases and the protective behavior is less likely to be enacted (18). Interestingly, according to a study performed on females, alcohol directly increased the risk through weaker future condom use intentions, but indirectly decreased the risk for women who were higher in condom use selfefficacy through stronger in-the-moment condom negotiation intentions (20), which is conceivable as alcohol might help to overcome shyness and enable a momentarily more decisive negotiation. According to another research, intoxicated people reported more prudent intentions than sober ones, provided that the most salient features of the situation emphasized the risks of unprotected sex (21), which also agrees with the alcohol myopia theory. The role of alcohol in safer sex decision making is broadly discussed in the literature, the prevailing opinion being that heavy binge drinking and alcohol consumption at sexual relations are risk factors for nonuse of condoms (2227). In particular, alcohol use was reported to be significantly associated with unprotected sex among people living with HIV/AIDS (28). Moreover, sexual violence often coincides with heavy alcohol use (29), whereas use of condoms within the context of violence would be less probable than on average $(30,31)$. However, alcohol consumption was reported to be inconsistently related to protective behaviors such as the condom use among college students (32). Some researchers did not find any correlation between drinking and lower condom use (33). There is a concept that people who use condoms when they are sober tend to use them also when they drink, whereas people who fail to use condoms when drinking probably also fail to use them when they are sober. However, empirical exceptions are recognized by the same researchers (18).

Psychological factors involved in risk perception related to alcohol consumption deserve a separate comment. It was demonstrated that young adults who have consumed alcohol perceive less risk than individuals who have not $(34,35)$. There is an opinion that pharmacologic effects of alcohol on cognitive processing contribute to risky sex, but only among persons who feel conflicted about risky sex, e.g., condom use (29). Several experimental studies have shown that alcohol intoxication interferes with the ability to evaluate the consequences of high-risk situations (35-38). The topic is not without controversy. In accordance with the cognitive impairment concept, a moderate dose of alcohol is supposed to interfere with recognition of ambiguous, but not clear, risk cues. For example, alcohol myopia effects impaired the intoxicated women's perception of less salient ambiguous cues, which might indicate increased risk of sexual assault, thus inhibiting precautions $(19,36,39)$. However, alcohol did not diminish women's perceptions of clear sexual assault risk cues (36). It should be commented that in the experimental studies (35-38), the intoxication level was relatively moderate, whereas at the doses typical for heavy binge drinking (e.g. over $300 \mathrm{~mL}$ of vodka plus beer or 
1.5l of fortified wine), perception of clear risks may decrease up to factual disappearance in a state of confusion or loss of consciousness, which was taken advantage of for sexual assaults and etc. Another issue is dependence of alcohol-related modification of risk perception from age and past experience of alcohol consumption. Multivariate analyses indicated that higher weekly alcohol use increased women's perceived risk to experience sexual intercourse as a result of a man's authority or administration of alcohol, i.e. women who were heavy drinkers perceived themselves at higher risk for sexual victimization than nondrinkers (40). On the contrary, in younger and less experienced people (students) in general, problematic use of alcohol is associated with novelty and popularity seeking (41) and hence with more risky behaviors. According to the author's observations, individuals with alcohol dependence and increased alcohol tolerance may preserve a high level of risk perception and behavioral skills in spite of intoxication. However, personality changes slowly progressing after a prolonged alcohol abuse and heavy binge drinking, discussed in the next paragraph, would sooner or later interfere with the risk perception and behavioral skills. The topic of risk perception regarding alcohol consumption and different stages of alcoholism needs a separate literature review and further studies.

Among personality traits and neural factors related to risk perception in drinkers, associated with irresponsible behaviors such as the nonuse of condoms, apparently are also those developing after a prolonged alcohol abuse, related to the deficit in frontal inhibitory control and cognitive impairment i.e. features compatible with organic personality disorder, frontal syndrome or alcoholrelated dementia $(42,43)$. The frontal lobe dysfunction has been defined as a hallmark of alcohol dependence (44); frontal lobes of alcoholics may shrink in volume with a decrease in neuron density $(45,46)$. The cortical changes and symptoms of alcohol-related dementia were reported to be similar to those in front temporal dementia (47). It should be mentioned that the term "alcoholic dementia", used in Russia does not exactly correspond to the internationally used term "alcohol-related dementia" (45), as old hematomas (48), traumatic brain injuries, nutritional deficiency and chronic diseases can play a role in pathogenesis (49). Among possible manifestations are social and personal neglect (47), insufficient foresight including a poor individual risk perception, disinhibition in the affective and emotional sphere (50), inability to forego small, immediate rewards for larger, delayed rewards (41). The topic "aggression and dementia" is beyond the scope of this letter; however, aggressive behavior is known to occur in patients with frontal syndrome (51). Note that reproductive coercion and contraception sabotage are regarded as a form of intimate partner violence (52). Birth control sabotage, pregnancy pressure and coercion can lead to reproductive health consequences and may be harmful for a woman's mental health (52). On the other hand, provocations and false accusations on the part of a female partner sometimes in complicity with third persons can occur as well.

\section{Conclusions}

The use of condoms in relation with alcohol drinking is largely dependent on personal characteristics; but taken on overage, heavy binge drinking and alcohol consumption at sexual relations are risk factors for the nonuse of condoms. However, data obtained by means of surveys in Russia are of limited value in this debate. In conclusion, surveys and opinion polls are valuable research tools and a feedback mechanism for administrative decisions (53); they should not be discredited by obtrusive questioning, asking for private information, with commercial and other purposes. Leakage of private information obtained by surveys must be efficiently precluded. Future efforts should be aimed at creation of an atmosphere of mutual trust between authorities, research institutions and the population, which would contribute to truthful answering to the questionnaires.

\section{Footnote}

Funding/Support: There was no grant support, funding, provision of equipment and supplies or financial support of any kind.

\section{References}

1. Stickley A, Koyanagi A, Koposov R, Razvodovsky Y, Ruchkin V. Adolescent binge drinking and risky health behaviours: findings from northern Russia. Drug Alcohol Depend. 2013;133(3):838-44. doi: 10.1016/j.drugalcdep.2013.08.028. [PubMed: 24080314].

2. Pomerleau J, McKee M, Rose R, Haerpfer CW, Rotman D, Tumanov S. Hazardous alcohol drinking in the former Soviet Union: a crosssectional study of eight countries. Alcohol Alcohol. 2008;43(3):351-9. doi: 10.1093/alcalc/agm167. [PubMed: 18245818].

3. Cook S, De Stavola B, Saburova L, Kiryanov N, Vasiljev M, McCambridge J, et al. Socio-demographic predictors of dimensions of the AUDIT score in a population sample of working-age men in Izhevsk, Russia. Alcohol Alcohol. 2011;46(6):702-8. doi:10.1093/alcalc/agr076. [PubMed: 21727097].

4. Lintonen T, Ahlstrom S, Metso L. The reliability of self-reported drinking in adolescence. Alcohol Alcohol. 2004;39(4):362-8. doi: 10.1093/alcalc/agh071. [PubMed: 15208172].

5. Bondarenko AG. Sociological research: survey methods (in Russian). Volgograd: Polytechnic; 2006.

6. Jargin SV. Barriers to the importation of medical products to Russia: in search of solutions. Healthcare in Low-Resource Settings. 2013;1:13. doi: 10.4081/hls.2013.e13. 
7. Jargin SV. Scientific misconduct Molodoi Uchenyi-Young Scientist; 2015. Available from: http://www.moluch.ru/archive/84/15613/.

8. Tourangeau R, Yan T. Sensitive questions in surveys. Psychol Bull. 2007;133(5):859-83. doi: 10.1037/0033-2909.133.5.859. [PubMed: 17723033].

9. Ottman R, Barker-Cummings C, Leibson CL, Vasoli VM, Hauser WA Buchhalter JR. Validation of a brief screening instrument for the ascertainment of epilepsy. Epilepsia. 2010;51(2):191-7. doi: 10.1111/j.15281167.2009.02274.x. [PubMed: 19694790].

10. Petroczi A, Nepusz T. Methodological considerations regarding response bias effect in substance use research: is correlation between the measured variables sufficient?. Subst Abuse Treat Prev Policy. 2011;6:1. doi: 10.1186/1747-597X-6-1. [PubMed: 21244663]

11. Berinsky AJ, Margolis M. Missing voices: polling and health care. J Health Polit Policy Law. 2011;36(6):975-87. doi: 10.1215/036168781460551. [PubMed: 22232421].

12. Jargin SV. Weak integrity and leakage: not only from microvessels. SAMJ Reader Comment; 2015.

13. United Nations . United Nations: World Abortion Policies; 2013. Available from: http://www.un.org/en/development/desa/population/ publications/policy/world-abortion-policies-2013.shtml.

14. Popov AA, Visser AP, Ketting E. Contraceptive knowledge, attitudes, and practice in Russia during the 1980s. Stud Fam Plann. 1993;24(4):227-35. [PubMed: 8212092].

15. Jargin SV. About the treatment of gonorrhea in the former Soviet Union. Dermatol Pract Concept. 2012;2(3):12. doi: 10.5826/dpc.0203a12. [PubMed: 23785614].

16. Jargin SV. Alcohol consumption by Russian workers before and during the economical reforms of the 1990s. Int J High Risk Behav Addict. 2013;2(2):48-50.

17. Griffin JA, Umstattd MR, Usdan SL. Alcohol use and high-risk sexual behavior among collegiate women: a review of research on alcohol myopia theory. J Am Coll Health. 2010;58(6):523-32. doi: 10.1080/07448481003621718. [PubMed: 20452928].

18. Weinhardt LS, Carey MP. Does alcohol lead to sexual risk behavior? Findings from event-level research. Annu Rev Sex Res. 2000;11:125-57. [PubMed: 11351830].

19. Steele CM, Josephs RA. Alcohol myopia. Its prized and dangerous effects. Am Psychol. 1990;45(8):921-33. [PubMed: 2221564].

20. Davis KC, Masters NT, Eakins D, Danube CL, George WH, Norris J, et al. Alcohol intoxication and condom use self-efficacy effects on women's condom use intentions. Addict Behav. 2014;39(1):153-8. doi: 10.1016/j.addbeh.2013.09.019. [PubMed: 24129265].

21. MacDonald TK, Fong GT, Zanna MP, Martineau AM. Alcohol myopia and condom use: can alcohol intoxication be associated with more prudent behavior?. J Pers Soc Psychol. 2000;78(4):605-19. [PubMed: 10794369].

22. Rehm J, Shield KD, Joharchi N, Shuper PA. Alcohol consumption and the intention to engage in unprotected sex: systematic review and meta-analysis of experimental studies. Addiction. 2012;107(1):51-9. doi: 10.1111/j.1360-0443.2011.03621.x. [PubMed: 22151318].

23. Sarkar NN. Barriers to condom use. Eur J Contracept Reprod Health Care. 2008;13(2):114-22. doi: 10.1080/13625180802011302. [PubMed: 18465472].

24. Eaton LA, Cain DN, Pitpitan EV, Carey KB, Carey MP, Mehlomakulu $\mathrm{V}$, et al. Exploring the relationships among food insecurity, alcohol use, and sexual risk taking among men and women living in South African townships. J Prim Prev. 2014;35(4):255-65. doi: 10.1007/s10935014-0346-3. [PubMed: 24806889].

25. Howells NL, Orcutt HK. Diary study of sexual risk taking, alcohol use, and strategies for reducing negative affect in female college students. J Stud Alcohol Drugs. 2014;75(3):399-403. [PubMed: 24766751].

26. Leigh BC, Stall R. Substance use and risky sexual behavior for exposure to HIV. Issues in methodology, interpretation, and prevention. Am Psychol. 1993;48(10):1035-45. [PubMed: 8256876].

27. Medic A, Dzelalija B, Kozul K, Novosel IP, Dijanic T. Risk factors in- fluencing non-use of condoms at sexual relations in populations under heightened risk. Coll Antropol. 2014;38(3):895-900. [PubMed: 25507355].

28. Scott-Sheldon LA, Walstrom P, Carey KB, Johnson BT, Carey MP, Mash Research Team. Alcohol use and sexual risk behaviors among individuals infected with HIV: a systematic review and meta-analysis 2012 to early 2013. Curr HIV/AIDS Rep. 2013;10(4):314-23. doi: 10.1007/s11904-0130177-5. [PubMed: 24078370].

29. Corte CM, Sommers MS. Alcohol and risky behaviors. Annu Rev Nurs Res. 2005;23:327-60. [PubMed: 16350769].

30. Davis KC, Danube CL, Neilson EC, Stappenbeck CA, Norris J, George WH, et al. Distal and proximal influences on men's intentions to resist condoms: Alcohol, sexual aggression history, impulsivity, and socialcognitive factors. AIDS Behav. 2015 doi: 10.1007/s10461-015-1132-9.

31. Bergmann JN, Stockman JK. How does intimate partner violence affect condom and oral contraceptive Use in the United States?: A systematic review of the literature. Contraception. 2015;91(6):438-55. doi: 10.1016/j.contraception.2015.02.009. [PubMed: 25708504].

32. Cooper ML. Alcohol use and risky sexual behavior among college students and youth: evaluating the evidence. J Stud Alcohol Suppl. 2002(14):101-17. [PubMed: 12022716].

33. Senf JH, Price CQ. Young adults, alcohol and condom use: what is the connection?.J Adolesc Health. 1994;15(3):238-44. doi:10.1016/1054139X(94)90509-6.

34. Maisto SA, Carey MP, Carey KB, Gordon CM, Schum JL. Effects of alcohol and expectancies on HIV-related risk perception and behavioral skills in heterosexual women. Exp Clin Psychopharmacol. 2004;12(4):288-97. doi: 10.1037/1064-1297.12.4.288. [PubMed: 15571446].

35. Fromme K, D’Amico EJ, Katz EC. Intoxicated sexual risk taking: an expectancy or cognitive impairment explanation?. J Stud Alcohol 1999;60(1):54-63. [PubMed: 10096309].

36. Davis KC, Stoner SA, Norris J, George WH, Masters NT. Women's awareness of and discomfort with sexual assault cues: effects of alcohol consumption and relationship type. Violence Against Women. 2009;15(9):1106-25. doi: 10.1177/1077801209340759. [PubMed: 19675365].

37. Fromme K, Katz E, D'Amico E. Effects of alcohol intoxication on the perceived consequences of risk taking. Exp Clin Psychopharmacol. 1997;5(1):14-23. [PubMed: 9234035].

38. Testa M, Livingston JA, Collins RL. The role of women's alcohol consumption in evaluation of vulnerability to sexual aggression. Exp Clin Psychopharmacol. 2000;8(2):185-91. [PubMed: 10843301].

39. Abbey A. Acquaintance rape and alcohol consumption on college campuses: how are they linked?.J Am Coll Health. 1991;39(4):165-9. doi: 10.1080/07448481.1991.9936229. [PubMed: 1995654].

40. Untied AS, Orchowski LM, Lazar V. College men's and women's respective perceptions of risk to perpetrate or experience sexual assault: the role of alcohol use and expectancies. Violence Against Women. 2013;19(7):903-23. doi: 10.1177/1077801213498216. [PubMed: 23955932].

41. Salameh P, Salame J, Waked M, Barbour B, Zeidan N, Baldi I. Risk perception, motives and behaviours in university students. Int $J$ Adolesc Youth. 2014;19(3):279-92. doi: 10.1080/02673843.2014.919599. [PubMed: 25431509].

42. Courtney KE, Polich J. Binge drinking in young adults: Data, def initions, and determinants. Psychol Bull. 2009;135(1):142-56. doi: 10.1037/a0014414. [PubMed:19210057].

43. Quemada JI, Sanchez-Cubillo I, Munoz-Cespedes JM. [Organic personality disorder: conceptual review and research strategies]. Actas Esp Psiquiatr. 2007;35(2):115-21. [PubMed: 17401782].

44. Nakamura-Palacios EM, de Almeida Benevides MC, da Penha ZagoGomes M, de Oliveira RW, de Vasconcellos VF, de Castro LN, et al. Auditory event-related potentials (P3) and cognitive changes induced by frontal direct current stimulation in alcoholics according to Lesch alcoholism typology. Int J Neuropsychopharmacol. 2012;15(5):601-16. doi 
10.1017/S1461145711001040. [PubMed: 21781352].

45. Ridley NJ, Draper B, Withall A. Alcohol-related dementia: an update of the evidence. Alzheimers Res Ther. 2013;5(1):3. doi: 10.1186/alzrt157. [PubMed: 23347747].

46. Sullivan EV, Harding AJ, Pentney R, Dlugos C, Martin PR, Parks $\mathrm{MH}$, et al. Disruption of frontocerebellar circuitry and function in alcoholism. Alcohol Clin Exp Res. 2003;27(2):301-9. doi: 10.1097/01.ALC.0000052584.05305.98. [PubMed: 12605080].

47. Brun A, Andersson J. Frontal dysfunction and frontal cortical synapse loss in alcoholism-the main cause of alcohol dementia?.Dement Geriatr Cogn Disord. 2001;12(4):289-94. [PubMed:11351140].

48. Persaud V. Morphologic studies on the non-cancerous cervix in Jamaicans at different ages. Int J Gynaecol Obstet. 1976;14(5):433-8. [PubMed: 15911].
49. Matsui T, Yokoyama A, Matsushita S, Kozaki K, Higuchi S. [Alcoholrelated dementia]. Nihon Rinsho. 2014;72(4):749-56. [PubMed: 24796110].

50. Fuster JM. The prefrontal cortex: Anatomy, physiology, and neuropsychology of the frontal lobe. 2 ed. New York: Raven Press; 1989.

51. Rommel O, Widdig W, Mehrtens S, Tegenthoff M, Malin JP. ['Frontal lobe syndrome' caused by severe head trauma or cerebrovascular diseases]. Nervenarzt. 1999;70(6):530-8. [PubMed:10412698].

52. Park J, Nordstrom SK, Weber KM, Irwin T. Reproductive coercion: uncloaking an imbalance of social power. Am J Obstet Gynecol. 2016;214(1):74-8. doi: 10.1016/j.ajog.2015.08.045. [PubMed: 26314520].

53. Bokii M, Shapiro L, Kirillov IU. Surveys in a city and for the city (in Russian). Obninsk: Institute of Municipal Management; 2002. 